\title{
Inhaled nitric oxide as a rescue therapy in a preterm neonate with severe pulmonary hypertension: a case report
}

\author{
Martina Busè ${ }^{1 *}$ D , Francesco Graziano ${ }^{1}$, Fabio Lunetta ${ }^{2}$, Giorgio Sulliotti ${ }^{2}$ and Vincenzo Duca ${ }^{2}$
}

\begin{abstract}
Background: Inhaled nitric oxide (iNO) has been approved for the treatment of persistent pulmonary hypertension of the newborn (PPHN) in term and near-term newborns. Its role in the management of persistent pulmonary hypertension in preterm infants is not clear. Although guidelines do not exist, some studies have shown that iNO could be used as a rescue therapy in preterm neonate with severe pulmonary hypertension.

Case presentation: We describe the case of a preterm neonate, born at $30+1$ weeks of gestation, with hypoxic respiratory failure not responding to maximal conventional therapy. On the third day of life echocardiography showed severe pulmonary hypertension with right to left shunt and therapy with iNO was started. We achieved a rapid improvement in clinical conditions and pulmonary pressure normalized after $42 \mathrm{~h}$ of treatment.

Conclusions: Moving on a case by case basis, treatment with iNO should be considered as a rescue therapy in preterm newborns with acute hypoxic respiratory failure caused by severe pulmonary hypertension.
\end{abstract}

Keywords: Inhaled nitric oxide, Preterm neonate, Pulmonary hypertension

\section{Background}

Persistent pulmonary hypertension of the newborn (PPHN) is a serious cardio-respiratory complication of the transition to extrauterine life. PPHN occurs mainly in term neonates, but it has also been detected in preterm neonates [1].

Inhaled nitric oxide (iNO) has been approved for the treatment of PPHN in term and near-term newborns. It was demonstrated that its selective vasodilatory action on the pulmonary circulation improves oxygenation and reduces the need for extracorporeal membrane oxygenation [2-7].

However, its role in the management of hypoxic respiratory failure due to pulmonary hypertension in preterm infants is not clear. Guidelines or standardized protocols do not exist, but some studies have shown that iNO could be used as a rescue therapy in preterm neonate with severe pulmonary hypertension who are not responding to maximal conventional therapy [8-13].

\footnotetext{
* Correspondence: mbuse@hotmail.it

'Dipartimento di Scienze per la Promozione della Salute e Materno Infantile

"Giuseppe D'Alessandro", University of Palermo, Palermo, Italy

Full list of author information is available at the end of the article
}

In the present paper, we describe the case of a preterm neonate, born at $30+1$ weeks of gestation (WG), with severe pulmonary hypertension treated with inhaled nitric oxide.

\section{Case presentation}

We report on the case of a female neonate born at $30+1$ WG by emergency caesarean section for preterm premature rupture of membranes (PPROM). She is the first born of a bichorionic and biamniotic twin pregnancy. At born: Apgar score 1' 5, 5' 8, birth weight 1380 g. She first needed nasal continuous positive airway pressure (CPAP), followed by orotracheal intubation. A dose of surfactant was administered, then the neonate was immediately transferred to our Neonatal Intensive Care Unit (NICU).

Upon arrival to our NICU, the patient appeared suffering, hypotonic with reduced reactivity; oxygen saturation was 93-94\% (inspired oxygen concentration ( $\mathrm{FiO} 2)$ 0.45) during synchronized intermittent positive pressure ventilation (SIPPV) and the abdomen appeared globose but treatable. She had emission of meconium with blood; blood and blood cores were suctioned from the oral 
cavity and stomach. Arterial blood gas analysis and routine investigations were normal. The coagulation was disrupted with prolonged prothrombin time and partial thromboplastin time and reduced antithrombin III activity (17\%). This was corrected by administration of antithrombin III.

In the following hours the patient's respiratory state deteriorated. Chest X-ray revealed the presence of pulmonary infiltrates, mainly to the left lung, and a second dose of surfactant was administered. Cranial ultrasound was normal. Echocardiography showed patent ductus arteriosus (PDA) and tricuspid insufficiency (PAPs $40-45 \mathrm{mmHg}$ ), but treatment was not started because of bleeding disorders.

On the second day of life echocardiography was repeated, showing PDA with pulsatile flow. The coagulation was normalized so we could start treatment with ibuprofen (first dose $10 \mathrm{mg} / \mathrm{Kg}$ ). Broad-spectrum antibiotics were initiated.

On the third day of life the patient's general conditions further deteriorated. Oxygen saturation was $80 \%$ during synchronized intermittent mandatory ventilation (SIMV) with $\mathrm{FiO} 20.80-0.90$. We observed a severe respiratory acidosis (pH 6.93, pCO2 $75 \mathrm{mmHg}$, bicarbonate $11 \mathrm{mmol} / \mathrm{l}$, base excess $-15.9 \mathrm{mmol} / \mathrm{l})$. A third dose of surfactant and sodium bicarbonate were administered; simultaneously continuous dopamine infusion was started. The oxygenation index (OI), calculated as $\mathrm{FiO} 2 \times$ Mean Airway Pressure $\times 100 / \mathrm{PaO} 2(\mathrm{mmHg})$, was 16. Echocardiography showed severe pulmonary hypertension (PAPs $77-80 \mathrm{mmHg}$ ) with right to left shunt (Fig. 1). Given the critical condition of the infant and the finding of severe pulmonary hypertension, we decided to stop ibuprofen and start therapy with iNO. iNO was started at the dose of 10 p.p.m. and the neonate was ventilated in SIPPV ( $\mathrm{FiO} 20.95$ ).

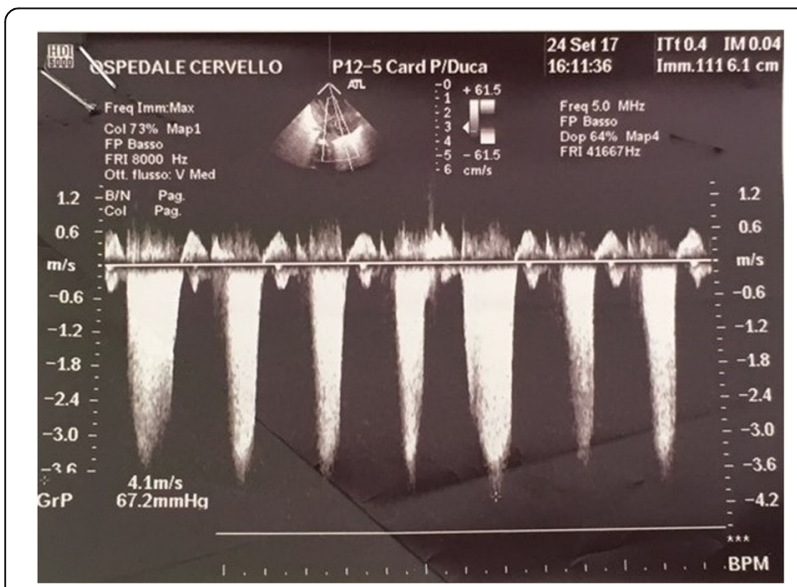

Fig. 1 Doppler ultrasound showing severe pulmonary hypertension: velocity of tricuspid regurgitant jet up to $4.1 \mathrm{~m} / \mathrm{sec}$
After $1 \mathrm{~h}$ iNO was increased to 15 p.p.m. and conventional mechanical ventilation was switched to high frequency oscillation ventilation (HFOV). Eight hours after starting treatment, oxygen saturation and blood gas parameters were improving and we reduced iNO to 13,10 and 7.5 p.p.m. gradually. At the same time conventional mechanical ventilation was restarted and FiO2 was progressively reduce to 0.50 .

After $42 \mathrm{~h}$ of treatment echocardiography showed normal pulmonary pressure and PDA with almost totally left to right shunt (Fig. 2a and b). Oxygenation index was 9. iNO was progressively stopped, reaching the complete suspension after $50 \mathrm{~h}$ from the start of treatment. The patient continued conventional mechanical ventilation (SIMV), gradually lowering the FiO2, and at $60 \mathrm{~h}$ from iNO suspension she was extubated.

Cranial ultrasound performed at $32+5$ WG was normal. Follow-up echocardiography was performed, the last (at $34 \mathrm{WG}$ ) showing normal pulmonary pressure, no shunts and closed ductus arteriosus.

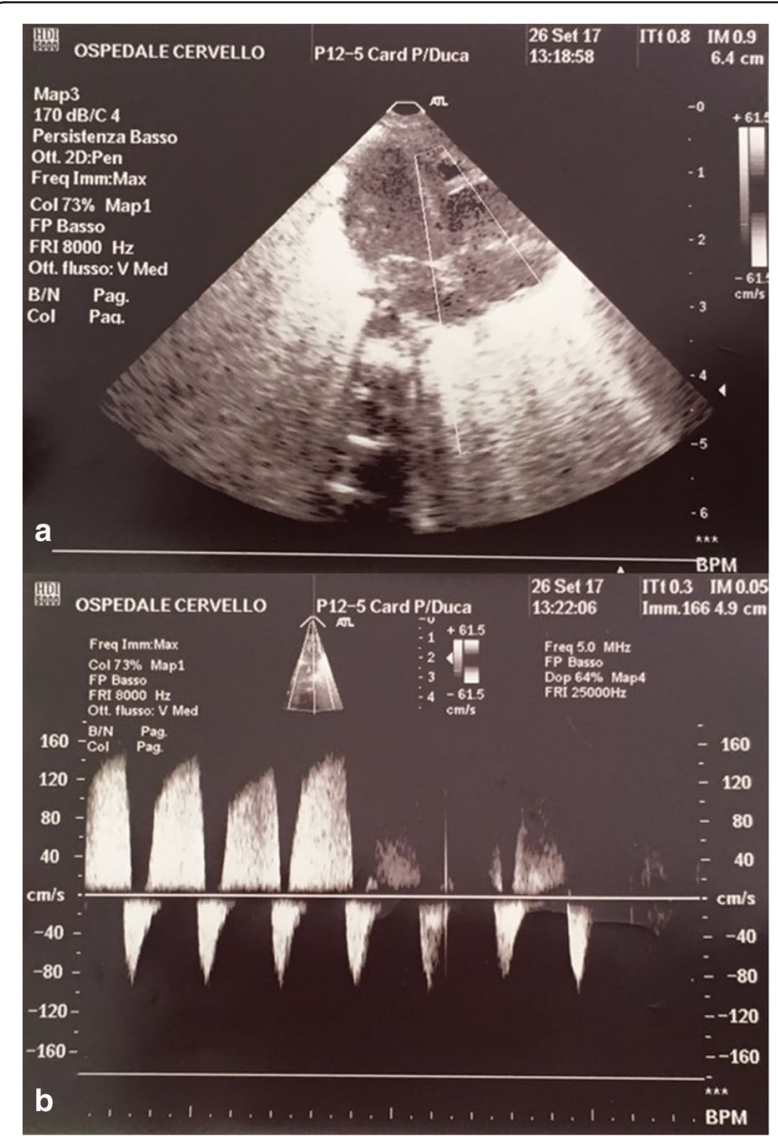

Fig. 2 a Echocardiography showing prevalence of right heart chambers. b Doppler ultrasound: sisto-diastolic flow with almost totally left to right shunt 


\section{Discussion and conclusions}

Although iNO has been approved for the treatment of PPHN in term and near-term newborns, the efficacy of this therapy for acute hypoxic respiratory failure owing to PPHN in premature neonates is not clear. Different studies have shown that iNO could be used as a rescue therapy in preterm neonates with severe pulmonary hypertension $[8,9]$. In particular, it seems that the response to iNO improves significantly with increasing gestational age: neonates born $\geq 29$ WG have a significantly greater response compared to neonates < 29 WG [10]. The most recent studies conclude that iNO therapy can improve the oxigenation in very preterm infants with PPHN, but it is not recommended for the routinely treatment and should be considered carefully. Moreover, they suggest that $\mathrm{FiO} 2>0.65$, echocardiographic diagnosis of PPHN, and birth weight $>750 \mathrm{~g}$ independently predict a beneficial effect of iNO in very preterm infants with RDS [12].

It is difficult to establish the cause of pulmonary hypertension in our patient, but it probably results from significant alteration of lung flows (with increased vasoconstrictive component) secondary to a maternal factors such as PPROM [10]. However, we cannot exclude that the administration of ibuprofen for PDA closure was the trigger that led to the onset of pulmonary hypertension. In fact, pulmonary hypertension is a rare but potentially lethal side effect in preterm infants receiving ibuprofen for PDA closure [14, 15].

After the finding of severe pulmonary hypertension, we started iNO therapy and we achieved a rapid improvement in clinical conditions. Treatment with iNO lasted a total of $50 \mathrm{~h}$; the maximum dose reached was 15 p.p.m. During treatment the maximum value of methemoglobin was $1,4 \%$. It is also important to note how the patient's conditions improved when iNO has been associated with HFOV rather than with conventional mechanical ventilation, confirming the effectiveness of the association between iNO and HFOV for the treatment of PPHN.

Our NICU does not have a standard protocol regarding the use of iNO in preterm infants. At the discretion of the clinical team, and moving on a case by case basis, iNO therapy is used in preterm neonates with PPHN when even maximal conventional therapy (FiO2 0.80-0.90) is not working.

In conclusion, our experience confirms that treatment with iNO should be considered as a rescue therapy in preterm newborns with acute hypoxic respiratory failure caused by severe pulmonary hypertension. Further studies and clinical trials are needed to better determine the real efficacy of this therapy in preterm and extremely preterm infants and to define guidelines and standard protocols.

\begin{abstract}
Abbreviations
CPAP: Continuous positive airway pressure; FiO2: Inspired oxygen concentration; HFOV: High frequency oscillation ventilation; iNO: Inhaled nitric oxide; NICU: Neonatal intensive care unit; OI: Oxygenation index; PDA: Patent ductus arteriosus; PPHN: Persistent pulmonary hypertension of the newborn; PPROM: Preterm premature rupture of membranes; SIMV: Synchronized intermittent mandatory ventilation; SIPPV: Synchronized intermittent positive pressure ventilation; WG: Weeks of gestation
\end{abstract}

\section{Acknowledgements}

We would like to thank the patient family, and all the participants of this study.

Funding

The authors declare no funding for this work.

Authors' contributions

All authors contributed in the same way to collect, analyze and interpret data and write the manuscript; all authors read and approved the final draft.

Ethics approval and consent to participate

Not applicable.

Consent for publication

Written informed consent was obtained from the patient's parents.

Competing interests

The authors declare that they have no competing interests.

\section{Publisher's Note}

Springer Nature remains neutral with regard to jurisdictional claims in published maps and institutional affiliations.

\section{Author details}

'Dipartimento di Scienze per la Promozione della Salute e Materno Infantile "Giuseppe D'Alessandro", University of Palermo, Palermo, Italy. 'Unità Operativa di Neonatologia e Terapia Intensiva Neonatale, AOOR Villa Sofia-Cervello, Palermo, Italy.

Received: 2 February 2018 Accepted: 8 May 2018

Published online: 15 May 2018

\section{References}

1. Walther FJ, Benders MJ, Leighton JO. Persistent pulmonary hypertension in premature neonates with severe respiratory distress syndrome. Pediatrics. 1992;90(6):899-904.

2. Roberts JD, Polaner DM, Zapol WM, Lang P. Inhaled nitric oxide in persistent pulmonary hypertension of the newborn. Lancet. 1992;340(8823):818-9.

3. Neonatal Inhaled Nitric Oxide Study Group. Inhaled nitric oxide in full-term and nearly full-term infants with hypoxic respiratory failure. N Engl J Med. 1997:336(9):597-604

4. Roberts JD Jr, Fineman JR, Morin FC, Shaul PW, Rimar S, Schreiber MD, The Inhaled Nitric Oxide Study group, et al. Inhaled nitric oxide and persistent pulmonary hypertension of the newborn. N Engl J Med. 1997;336(9):605-10.

5. Al-Alaiyan S, Neiley E. Inhaled nitric oxide in persistent pulmonary hypertension of the newborn refractory to high-frequency ventilation. Crit Care. 1999;3(1):7.

6. Clark RH, Kueser TJ, Walker MW, Southgate WM, Huckaby JL, Perez JA, Roy BJ, Keszler M, Kinsella JP. Low-dose nitric oxide therapy for persistent pulmonary hypertension of the newborn. N Engl J Med. 2000;342(7):469-74.

7. Barrington KJ, Finer N, Pennaforte T, Altit G. Nitric oxide for respiratory failure in infants born at or near term: The Cochrane Library; 2017.

8. Kinsella JP, Cutter GR, Walsh WF, Gerstmann DR, Bose CL, Hart C, Sekar KC, Auten RL, Bhutani VK, Gerdes JS, George TN, Southgate WM, Carriedo H, Couser RJ, Mammel MC, Hall DC, Pappagallo M, Sardesai S, Strain JD, Baier M, Abman SH. Early inhaled nitric oxide therapy in premature newborns with respiratory failure. N Engl J Med. 2006;355(4):354-64.

9. Donohue PK, Gilmore MM, Cristofalo E, Wilson RF, Weiner JZ, Lau BD, Robinson KA, Allen MC. Inhaled nitric oxide in preterm infants: a systematic review. Pediatrics. 2011;127(2):e414-22. 
10. Kumar VH, Hutchison AA, Lakshminrusimha S, Morin FC, Wynn RJ, Ryan RM. Characteristics of pulmonary hypertension in preterm neonates. J Perinatol. 2007;27(4):214-9.

11. Barrington $\mathrm{K}$, Finer $\mathrm{N}$, Pennaforte T. Inhaled nitric oxide for respiratory failure in preterm infants. Cochrane Database Syst Rev. 2017;

12. Dani C, Corsini I, Cangemi J, Vangi V, Pratesi S. Nitric oxide for the treatment of preterm infants with severe RDS and pulmonary hypertension. Pediatr Pulmonol. 2017;52(11):1461-8.

13. Baczynski M, Ginty S, Weisz DE, McNamara PJ, Kelly E, Shah P, Jain A. 2017. Short-term and long-term outcomes of preterm neonates with acute severe pulmonary hypertension following rescue treatment with inhaled nitric oxide. Archives of disease in childhood-fetal and neonatal edition, fetalneonatal-2016.

14. Gournay V, Savagner C, Thiriez G, Kuster A, Roze JC. Pulmonary hypertension after ibuprofen prophylaxis in very preterm infants. Lancet. 2002;359(9316):1486-8.

15. Bellini C, Campone F, Serra G. Pulmonary hypertension following L-lysine ibuprofen therapy in a preterm infant with patent ductus arteriosus. Can Med Assoc J. 2006;174(13):1843-4.

Ready to submit your research? Choose BMC and benefit from:

- fast, convenient online submission

- thorough peer review by experienced researchers in your field

- rapid publication on acceptance

- support for research data, including large and complex data types

- gold Open Access which fosters wider collaboration and increased citations

- maximum visibility for your research: over $100 \mathrm{M}$ website views per year 